\title{
The incidence and etiology of postpartum headaches: a prospective cohort study
}

\section{[L'incidence et la cause des céphalées du postpartum : une étude prospective]}

Eric Goldszmidt MD, ${ }^{*}$ Ralph Kern MD MHSc, $†$ Alan Chaput PHARMd MD MSc, ${ }^{*}$ Alison Macarthur MD MSc ${ }^{*}$

Purpose: We sought to determine the incidence, etiology, characteristics and risk factors for all headaches in the first week postpartum.

Methods: This was a prospective cohort study of 985 women delivering over a three-month period in a single tertiary-care institution. These women underwent a structured interview and follow-up to collect demographic data and to assess for the presence and characteristics of postpartum headache (PPHa) or neck/shoulder pain. All headaches were diagnosed using an algorithm based on the diagnostic criteria of the International Headache Society. Multivariate analysis was used to examine possible risk factors.

Results: Three hundred eighty-one of the 985 study participants (39\%) reported headaches or neck/shoulder pain during the study period. The median time to onset of the PPHa was two days $(0,6$; Ist and 3rd quartiles) and duration was four hours (2, 24; Ist and 3rd quartiles). Primary headaches accounted for $>75 \%$ of PPHa. Only a small number of headaches $(4 \%)$ were incapacitating. Postdural puncture headache accounted for $4.7 \%$ of all PPHa. Significant risk factors for the development of PPHa were: known inadvertent dural puncture [odds ratio $(\mathrm{OR})_{\mathrm{adj}}$ $=6.36 ; 95 \%$ confidence interval $(\mathrm{Cl})$ I.29, 31.24]; previous headache history $\left(\mathrm{I}-\mathrm{I} 2 / \mathrm{yr}-\mathrm{OR}_{\mathrm{adj}}=1.57 ; 95 \% \mathrm{Cl} \mathrm{I} .0 \mathrm{I}, 2.44 ;>\right.$ $\left.\mathrm{I} 2 / \mathrm{yr}-\mathrm{OR}_{\mathrm{adj}}=2.25 ; 95 \% \mathrm{Cl} \mathrm{I} .63,3 . \mathrm{II}\right)$; multiparity $\left(\mathrm{OR}_{\mathrm{adj}}=\right.$ I.37; $95 \% \mathrm{Cl} 1.03, \mathrm{I} .82)$ and increasing age $\left(\mathrm{OR}_{\mathrm{adj}}=1.03 / \mathrm{yr}\right.$; $95 \% \mathrm{Cl} 1.00,1.06)$.

Conclusions: Postpartum headaches are common, often first noted after discharge from hospital. The majority are related to primary headache disorders. Increased awareness of this epidemiological relationship and improved diagnosis of primary headache conditions may lead to improved headache-specific therapy and avoidance of unnecessary investigations or readmission to hospital.
Objectif : Déterminer l'incidence, la cause, les caractéristiques et les facteurs de risque de toutes les céphalées de la première semaine du postpartum.

Méthode : L'étude a porté sur 985 femmes qui ont accouché au cours d'une période de trois mois dans un hôpital de soins tertiaires. Une entrevue structurée a été suivie d'un examen de contrôle pour recueillir les données démographiques et évaluer la présence et les caractéristiques des céphalées du postpartum (CPP) ou des douleurs au cou ou aux épaules. Un algorithme fondé sur les critères de diagnostic de l'International Headache Society a servi à identifier toutes les céphalées. La recherche de facteurs de risque possibles a été faite grâce à une analyse multivariée.

Résultats : Sur les 985 participantes, 381 (39\%) ont eu des céphalées ou des douleurs au cou ou aux épaules. Le délai moyen d'apparition des CPP a été de deux jours $\left(0,6 ; I^{\mathrm{er}}\right.$ et $3^{\mathrm{e}}$ quartiles) et la durée de quatre heures $\left(2,24 ; 1^{\text {er }}\right.$ et $3^{\mathrm{e}}$ quartiles). Les céphalées primaires comptaient pour $>75 \%$ des CPP. Peu de céphalées (4 $\%)$ ont été incapacitantes. Les céphalées post ponction durale comptaient pour 4,7 \% des CPP. Les facteurs de risque significatifs de développement des CPP ont été : une ponction de la dure-mère involontaire connue [risque relatif $(R R)_{a j u}=6,36$; intervalle de confiance de $95 \%$ (IC) I,29, 3I,24]; des antécédents de céphalées (I-I2/an- $R R_{a j u}=1,57$; IC de $95 \%$ I,0I, 2,44; > I2/an- $R R_{a j u}$ $=2,25$; IC de $95 \% I, 63,3, I I)$; la multiparité $\left(R R_{a j u}=I, 37\right.$; IC de $95 \%$ I,03, I,82) et l'âge croissant $\left(R R_{a j u}=1,03 /\right.$ an ; IC de $95 \%$ 1,00, I,06).

Conclusion: Les céphalées du postpartum sont fréquentes, souvent notées après le départ de l'hôpital. Elles sont en majorité primaires. Une meilleure connaissance de cette relation épidémiologique et du diagnostic des céphalées primaires peut améliorer le traitement de céphalées spécifiques et permet d'éviter des examens inutiles ou la réadmission à l'hôpital.

From the Departments of Anesthesia and Pain Management, ${ }^{*}$ and Neurology, $†$ Mount Sinai Hospital; University of Toronto, $\ddagger$ Toronto, Ontario, Canada.

Address correspondence to: Dr. Eric Goldszmidt, University of Toronto, 600 University Avenue \#1514, Toronto, Ontario, Canada M5G 1X5. Phone: 416-586-5270; Fax: 416-586-8664; E-mail: e.goldszmidt@utoronto.ca

Funding: Crystal Chettle was supported by a University of Toronto Summer Research Bursary.

Conflicts of interest: none.

Accepted for publication April 11, 2005.

Revision accepted June 7, 2005. 
$\mathrm{H}$ EADACHES occurring during the postpartum period may be primary or secondary. Primary headaches include migraine, ${ }^{1}$ tension-type, ${ }^{2}$ cervicogenic ${ }^{3}$ and cluster headaches. ${ }^{4}$ These occur frequently in the normal population ${ }^{5}$ and may be observed in the postpartum period. Secondary headaches include headaches due to regional anesthesia complications [e.g., postdural puncture headache (PDPH)], obstetrical disease (e.g., hypertensive disorders) or intracranial pathology (e.g., cerebral venous thrombosis).

Anesthesiologists and neurologists are frequently called upon to assess postpartum headaches, particularly in patients who have had regional anesthesia. These headaches are also commonly encountered by obstetricians and family physicians. Our study objective was to determine the frequency of primary and secondary postpartum headaches, in our patient population, determine the etiology and characteristics of these headaches and identify possible risk factors.

\section{Materials and methods}

With hospital Research Ethics Board approval, women who delivered at Mount Sinai Hospital, Toronto, Canada (a tertiary care teaching hospital) and were $>20$ weeks gestation at the time of delivery were approached to participate in this prospective cohort study. Enrollment occurred five days per week. Patients were excluded if they declined to participate or if they were unable to communicate. Patients were enrolled between June 1 and Sept. 3, 2003. The primary outcome was the incidence of a postpartum headache or neck/shoulder pain within one week of delivery.

Those who consented underwent a structured interview (in person or by telephone if already discharged) and chart review within $72 \mathrm{hr}$ of delivery administered by one research assistant. Information was collected on maternal demographics, labour and delivery demographics, anesthesia during labour and delivery, and headache characteristics and management. All women with headaches at the time of interview were contacted daily until resolution of their symptoms. All other participants were reassessed at one week by telephone. Women with recurring headaches were only counted once in estimating the incidence of postpartum headaches.

Regional anesthesia was performed by residents, fellows and staff as per our routine. We use 17G Tuohy needles for epidurals. During the study period, the spinal portion of combined spinal epidurals (CSE) was done with $26 \mathrm{G}$ Whitacre needles while single-shot spinals were done with $25 \mathrm{G}$ Whitacre needles.

Headache diagnoses were made using an algorithm based on the diagnostic criteria of the International
Headache Society (Appendix). ${ }^{6}$ The diagnoses were arrived at independently by an anesthesiologist (E.G.) and a neurologist (R.K.). Any discrepancies were reviewed and classified by consensus of the two physicians.

\section{Statistical analysis}

Data were analyzed using STATA version 8.0 (College Station, TX, USA). The primary outcome, incidence of postpartum headache, was calculated as the proportion of women who developed at least one postpartum headache with $95 \%$ confidence intervals (CI) calculated using exact binomial methods. Secondary continuous outcomes were summarized as medians with lst and 3rd quartiles, while binomial and categorical outcomes were summarized as proportions.

A nested case-control analysis was done to evaluate possible risk factors for postpartum headaches. Women who developed at least one postpartum headache (cases) were compared to women who did not develop a postpartum headache (controls). Initial univariate comparisons were conducted for ten potential risk factors: maternal age (yr), ethnicity (self described choice from modified Statistics Canada list of seven categories), parity (primiparous, multiparous), past headache history (none, $<12 / \mathrm{yr},>12 / \mathrm{yr}$ ), duration of labour (hours reported from start of regular, painful contractions to delivery of infant), duration of pushing during second stage (minutes noted by nurse of active participation during second stage), method of analgesia/anesthesia for labour and delivery (ten categories), anesthesia operator experience ( $<85$ epidurals inserted, $>85$ epidurals inserted), use of air to identify epidural space (yes/no as recorded on anesthesia record) and inadvertent dural puncture during epidural anesthesia (yes/no as commented on in the anesthesia record). The distribution of risk factors between the two groups were described either by crude odds ratios (OR) or by comparison between means. Continuous variables were compared using the two-tailed Student t test, using $P<0.05$ as the designated level of statistical significance. Binary variables were compared using the Fisher's exact test for proportions, and categorical variables with more than two groups were compared using logistic regression with the same level of statistical significance. Ninety-five percent CI were estimated for all analyses. Adjusted OR for the development of postpartum headache were estimated using logistic regression multivariate analysis. Modeling was conducted using a backward stepwise progression method. The full model consisted of a priori defined variables including previous headache history and known inadvertent dural puncture, as well 
TABLE I Etiology of postpartum headaches

\begin{tabular}{ll}
\hline Headache Type & Number (\% of postpartum headaches) \\
\hline Tension-type & $146(38.3 \%)$ \\
Migrainous & $102(26.8 \%)$ \\
Musculoskeletal & $43(11.3 \%)$ \\
Undetermined & $31(8.1 \%)$ \\
Migraine without aura & $24(6.3 \%)$ \\
Postdural puncture & $18(4.7 \%)$ \\
Cervicogenic & $13(3.4 \%)$ \\
Migraine with aura & $4(1 \%)$ \\
Cluster, secondary & 0 \\
Total & $381(100 \%)$ \\
\hline
\end{tabular}

TABLE II Functional severity of postpartum headaches

\begin{tabular}{ll}
\hline Functional capacity & Number (\% of headaches) \\
\hline $\begin{array}{l}\text { Able to take care of self and baby } \\
\text { Mother able to take care of self, }\end{array}$ & $766(96.1 \%)$ \\
$\begin{array}{l}\text { but not baby } \\
\begin{array}{l}\text { Mother bed-ridden, unable to care } \\
\text { for self or baby }\end{array}\end{array}$ & $8(2.1 \%)$ \\
\hline
\end{tabular}

as any variable with a significant difference $(P<0.1)$ found on univariate analysis. Removal of insignificant variables occurred following statistical evaluation of two successive models using the likelihood ratio statistic $(P<0.05)$. The final model was assessed for goodness of fit using the Pearson Chi- square statistic, and predictive test probabilities.

Sample size calculation was based upon the expected headache incidence in our population. European surveys have documented postpartum headache incidence rates between 13 and $39 \% \%^{7,8}$ Over a 12 -week study period, we expected to identify between 125 and 374 women with postpartum headaches (based on an $80 \%$ capture rate, five days/week, of approximately 20 deliveries/day). With this number of women with expected postpartum headaches, we used a rule of thumb to estimate the number of cases required to evaluate the association between potential risk factor and outcome in multivariate analysis. Approximately ten cases and ten controls per binomial predictive risk factor, so we expected to have sufficient power to evaluate a maximum of ten potential risk factors within a multivariate logistic regression model. ${ }^{9}$

\section{Results}

During the study period, 1,054 (65.7\%) women amongst a delivery population of 1,605 were approached. Consent was obtained from 93\% $(985 / 1,054)$ of those approached.

Three hundred eighty-one of 985 women $(38.7 \%$; 95\% CI: 36\%, 42\%) reported postpartum headache or neck/shoulder pain. The median time to onset of symptoms was two days postpartum $(0,6$; lst and $3 \mathrm{rd}$ quartiles). The median duration of the headache was four hours $(2,24 ; 1$ st and 3rd quartiles). The etiologies are shown in Table I.

The median maximum intensity of the postpartum headache, using a ten-point verbal analogue scale, was $5.0(3.0,7.0 ; 1$ st and 3 rd quartiles). The majority of women with postpartum headaches were able to function, with only 15 patients $(3.9 \%)$ having incapacitating headaches (Table II). Twelve of these were primary headaches and three were PDPH. Despite a lower incidence, PDPH were five times more likely to be incapacitating compared to other causes of postpartum headache (relative risk 5.2; 95\% CI: 1.62-16.74).

Inexperienced residents performed $40 \%$ of the epidurals during the study period but accounted for $89 \%$ of the recognized large bore dural punctures. Table III shows the different grades of epidural operators and their incidence of recognized dural puncture.

At our institution, a teaching site for anesthesia residents, the incidence of PDPH was $1.8 \%$ (18/985). Of these 18 headaches, four occurred following single-shot spinal anesthesia ( $2.2 \%$ of all spinals) while the remaining 14 occurred following epidural anesthesia. Only six of these 14 patients had their dural punctures recognized at the time of epidural insertion (Table IV). No PDPH was documented following CSE. Although we only diagnosed $18 \mathrm{PDPH}, 81$ of 381 women with headaches $(21 \%)$ reported symptomatic relief when supine. Of these, 78 had a regional

TABLE III Epidural operators and incidence of dural puncture

\begin{tabular}{|c|c|c|c|c|c|}
\hline & Residents with $<85$ insertions & Residents with $>85$ insertions & Fellows & Staff & Total \\
\hline $\begin{array}{l}\text { Number of epidurals and CSE } \\
n \text { (\% of total) }\end{array}$ & $273(40 \%)$ & $99(15 \%)$ & $110(16 \%)$ & $197(29 \%)$ & $679(100 \%)$ \\
\hline $\begin{array}{l}\text { Recognized large bore dural puncture } \\
n \text { (\% of total) }\end{array}$ & $8(89 \%)$ & 0 & 0 & $1(11 \%)$ & $9(100 \%)$ \\
\hline
\end{tabular}

$\mathrm{CSE}=$ combined spinal epidural. 
TABLE IV Headaches and neuraxial anesthesia

\begin{tabular}{|c|c|c|c|c|}
\hline & Epidural & CSE & Spinal & All neuraxial anesthesia \\
\hline $\begin{array}{l}\text { Total performed } \\
n \text { (\% of all study patients) }\end{array}$ & $608(62 \%)$ & $81(8 \%)$ & $184(19 \%)$ & $873(89 \%)$ \\
\hline $\begin{array}{l}\text { Recognized large-bore dural punctures } \\
n \text { (\% of total performed) } \\
\text { PDPH }\end{array}$ & $9(1.5 \%)^{*}$ & 0 & $x^{2}+2$ & $9(1.0 \%)$ \\
\hline $\begin{array}{l}n(\% \text { of total performed }) \\
\text { Non-PDPH }\end{array}$ & $14(2.3 \%) \dagger$ & 0 & $4(2.2 \%)$ & $18(2.1 \%)$ \\
\hline$n(\%$ of total performed $)$ & $219(36 \%)$ & $37(46 \%)$ & $68(37 \%)$ & $324(37 \%)$ \\
\hline
\end{tabular}

$\mathrm{CSE}=$ combined spinal epidural, $\mathrm{PDPH}=$ postdural puncture headache. ${ }^{*}$ Six out of nine patients with recognized dural punctures had a PDPH, one had a migrainous headache †Seven out of 14 patients with PDPH in the epidural group did not have recognized dural punctures.

TABLE V Risk factor analysis for postpartum headaches

\begin{tabular}{|c|c|c|}
\hline Risk factor for postpartum headache & Crude OR $(95 \%$ CI $)$ & Adjusted OR (95\% CI) \\
\hline \multicolumn{3}{|l|}{$\begin{array}{l}\text { Previous headache history } \\
\text { (vs no previous headache) }\end{array}$} \\
\hline -1-12 headaches/year & $\begin{array}{l}1.57 \\
(1.02,2.42)\end{array}$ & $\begin{array}{l}1.57 \\
(1.01,2.44)\end{array}$ \\
\hline - $>12$ headaches/year & $\begin{array}{l}2.06 \\
(1.50,2.82)\end{array}$ & $\begin{array}{l}2.25 \\
(1.63,3.11)\end{array}$ \\
\hline $\begin{array}{l}\text { Multiparous } \\
\text { ( } v s \text { primiparous) }\end{array}$ & $\begin{array}{l}1.50 \\
(1.16,1.94)\end{array}$ & $\begin{array}{l}1.37 \\
(1.03,1.82)\end{array}$ \\
\hline $\begin{array}{l}\text { Age in yr } \\
\text { (compared to women one year younger) }\end{array}$ & $\begin{array}{l}1.04 \\
(1.01,1.06)\end{array}$ & $\begin{array}{l}1.03 \\
(1.00,1.06)\end{array}$ \\
\hline Identified inadvertent dural puncture with epidural needle & $\begin{array}{l}5.63 \\
(1.16,27.3)\end{array}$ & $\begin{array}{l}6.36 \\
(1.29,31.24)\end{array}$ \\
\hline $\begin{array}{l}\text { Ethnicity } \\
\text { (vs Caucasian) }\end{array}$ & 0.68 & Not included in final \\
\hline -Asian & $\begin{array}{l}(0.46,1.00) \\
0.93\end{array}$ & multivariate model \\
\hline • Other & $(0.64,1.35)$ & \\
\hline $\begin{array}{l}\text { Use of neuraxial anesthesia } \\
\text { ( } v s \text { no neuraxial) }\end{array}$ & $\begin{array}{l}1.21 \\
(0.80,1.82)\end{array}$ & $\begin{array}{l}\text { Not included in final } \\
\text { multivariate model }\end{array}$ \\
\hline Use of loss of resistance to air technique ( $v s$ saline) & $\begin{array}{l}0.85 \\
(0.66,1.10)\end{array}$ & $\begin{array}{l}\text { Not included in final } \\
\text { multivariate model }\end{array}$ \\
\hline $\begin{array}{l}\text { Fellow/staff performing procedure } \\
\text { (vs resident) }\end{array}$ & $\begin{array}{l}1.24 \\
(0.94,1.62)\end{array}$ & $\begin{array}{l}\text { Not included in final } \\
\text { multivariate model }\end{array}$ \\
\hline $\begin{array}{l}\text { Duration of labour } \\
\text { (compared to labour one hour less) }\end{array}$ & $\begin{array}{l}0.99 \\
(0.98,1.01)\end{array}$ & $\begin{array}{l}\text { Not included in final } \\
\text { multivariate model }\end{array}$ \\
\hline $\begin{array}{l}\text { Duration of pushing in second stage } \\
\text { (compared to women pushing for } 30 \text { min less) }\end{array}$ & $\begin{array}{l}0.88 \\
(0.81,0.98)\end{array}$ & $\begin{array}{l}0.90 \\
(0.81,1.00)\end{array}$ \\
\hline
\end{tabular}
$\mathrm{OR}=$ odds ratio; $\mathrm{CI}=$ confidence interval. 
anesthetic, and one had a difficult epidural attempt abandoned. All of these headaches better fit other diagnostic criteria as per our algorithm.

Univariate analysis identified the following risk factors for postpartum headaches which were included in the multivariate logistic regression: inadvertent dural puncture, previous headache history, multiparity, age, and duration of second stage pushing (Table V). In other words, women with a previous headache history, with an inadvertent dural puncture, who were multiparous, older, and pushed for less time were more likely to experience postpartum headaches. These risk factors remained significant when taking into account the effect of other risk factors (adjusted OR in Table V).

A combination of physician and self-directed analgesic regimens were used by patients in the postpartum period. The most commonly used analgesic to treat postpartum headache was acetaminophen which was consumed by $47.0 \%$ of patients. Non-steroidal anti-inflammatories, oral opioids and parenteral opioids were taken by $34.4 \%, 12.3 \%$ and $0.3 \%$ of patients respectively. No patients were treated with caffeine.

Four of the 18 patients with PDPH were treated with epidural blood patch; three of these four patients had recognized dural punctures. Two of these had neurological investigations (one computerized tomography scan; one magnetic resonance imaging) prior to administering a second blood patch at the discretion of the attending anesthesiologist. Neurological imaging is not a standard of practice in investigating suspected PDPH, however in these cases the anesthesiologist felt it important in ruling out other pathology prior to administering an epidural blood patch. No intracranial pathologies or infectious processes were found during these investigations, and no other patient required any neurological investigations.

\section{Discussion}

In our prospective cohort study of postpartum headaches, we found that $39 \%$ of women experienced some form of headache syndrome during the first postpartum week. The onset of their headache was usually in the first few days after delivery. The most common types of headaches were tension and migrainous. Although many of these headaches were of at least moderate severity, only $4 \%$ resulted in significant functional impairment. The most significant risk factors for the development of postpartum headache were: inadvertent dural puncture, previous headache history, multiparity, shorter pushing in second stage of labour and increased maternal age.

With the exception of PDPH, all other headaches in this cohort were primary in nature. This is not surprising considering the rarity of other secondary headache syndromes. Primary headaches were 20 times more common than PDPH. Also observed was the fact that PDPH made up only $21 \%$ of all headaches with postural symptoms. This must be kept in mind when assessing patients with PPHa, as this high background of primary headaches may confound the diagnosis of PDPH.

This study was comprehensive in that it identified the etiology of all headaches in the postpartum population and assessed characteristics of postpartum headaches and their management. Other studies have described smaller subpopulations of women with postpartum headaches. ${ }^{7,8,10,11}$ Stein prospectively surveyed two small groups of randomly chosen women $(n=$ 40 and 71 ) and found the incidences to be $37 \%^{10}$ and $39 \%,{ }^{8}$ similar to the incidence in our study. The largest proportion of postpartum headaches occurred between the third and sixth postpartum day. In Grove's study of 187 women who did not have epidural analgesia, he documented a $23 \%$ incidence of postpartum headaches, with the majority occurring on the first and second postpartum days. ${ }^{11}$ In contrast to these results, Benhamou et al. found the incidence to be only $13 \%$ in a cohort of 1,198 women who returned a mail-out questionnaire following delivery. ${ }^{7}$ This study, however, had only a $41 \%$ response rate to their questionnaire.

Other papers have attempted to identify risk factors for postpartum headaches, although ours is the first to use multivariate analysis to adjust for effects of several risk factors. Similar to our findings, others have also found that a history of previous headaches is a significant risk factor for the development of postpartum headaches. ${ }^{7,8,10}$ Stein et al. ${ }^{8}$ and Maggioni et al. ${ }^{12}$ also found an increased incidence in multiparous women. Perhaps one explanation is that multiparous women have more complicated lives after delivery as compared to primiparous women. The anesthesia literature has long recognized the problems of inadvertent dural puncture with an epidural needle. The large gauge of the needle allows for CSF escape and lowered intracranial pressure. Most times, the headache resolves with adequate hydration and oral analgesics. ${ }^{13}$ Additional risk factors not examined in our study were pregnancy induced hypertension, ${ }^{7}$ maternal weight changes, ${ }^{10}$ estrogen levels, ${ }^{8}$ history of menstrual migraine or previous PPHa. Estrogen is of particular importance because postpartum migraine may be related to falling estrogen levels. ${ }^{14}$ We were surprised by the protective effect of longer pushing during labour and cannot explain why this factor reduced the incidence of postpartum headaches. 
The strength of this study lies in its size and scope. Our sample size was large and the participation rate of $93 \%$ makes it unlikely that our results are biased by non-responders. Our follow-up protocol included early postpartum contact, daily follow-up for headache sufferers and a one-week contact phone call. It is likely that these repeated contacts helped with the fidelity of our natural history data and limited the amount of distortion due to poor patient recall. Ideally we would have liked to continue telephone surveillance for a further five weeks, until the end of the postpartum period, however our resources were limited. We felt that the first week was of most importance, in that women during this week would need the most help while adjusting to the new arrival of their baby.

The high incidence of primary postpartum headaches should be kept in mind by health care providers caring for postpartum women, and should be included in antenatal descriptions of this period. Anesthesiologists must remember that many primary headaches may have postural features and that up to $50 \%$ of our PDPH occurred without a recognized dural puncture. The only article that alludes to this suggested the incidence was approximately $35 \%{ }^{15}$ Most of our labour epidural catheters are inserted by junior trainees, which may be a contributing factor. In our study, the observed rate of epidural blood patch was quite low $(4 / 18=22 \%)$. We do not believe that it is related to whether or not the dural puncture was recognized. We have consistently observed that our patient population is quite reluctant to undergo blood patching unless they are severely affected despite conservative management. Also, our department does not usually encourage a blood patch unless the patient cannot manage her usual activities. These factors probably account for the low incidence which was expected in our institution.

The postpartum period is characterized by maternal fatigue, sleep deprivation, stress, fluid shifts, weight changes and estrogen-withdrawal. All of these may contribute to the incidence of primary headaches. Unfortunately, postpartum headaches may go unrecognized and remain poorly treated, as they are likely to occur following discharge. Primary care physicians need to be alerted to this problem and ensure that adequate analgesics and instructions as to their optimal use are available. This is especially true of patients with a prior history of headache or an inadvertent large bore dural puncture who should be singled out for warnings and instructions in dealing with their headache prior to discharge from hospital. This may help to limit morbidity and anxiety as well as to avoid the difficulties associated with a return visit to a clinic or emergency room. It is already known that women with PDPH have an increased incidence of emergency room visits. ${ }^{16}$ One must also remain vigilant for very rare, but life-threatening causes of headache such as intracranial hemorrhage, cerebral venous thrombosis, raised intracranial pressure or meningitis. Typically these secondary causes present with headache, altered level of consciousness, and neurological deficits. ${ }^{17}$

Future studies of primary headaches should prospectively evaluate postpartum migraine and estrogen levels, and correlate these with a history of menstrual migraine which is also thought to be related to estrogen withdrawal. This subgroup may also be followed into the non-pregnant period to examine possible changes in headache frequency.

\section{Acknowledgements}

Special thanks to Crystal Chettle for data collection and Dr. Isabella Devito for help with study conception and design.

\section{APPENDIX Diagnostic algorithm}

\section{A. Migraine without aura:}

i. At least 2 of the following:

- Unilateral

- Throbbing

- Moderate or severe intensity

- Aggravated by routine physical activity

ii. During headache at least one of the following:

- Nausea or vomiting

- Photophobia or phonophobia

B. Migraine with aura:

i. Above

ii. Reversible visual symptoms

- Less than 60 minutes duration

- Scintillating scotoma, shimmering or pulsating quality

iii. Migrating sensory symptoms

iv. Other causes excluded

C. Tension-type headache

- Constricting, circumferential pressure-like pain

- Mild to moderate severity

- Scalp tenderness

D. Cervicogenic headache

- Cervical pain

- Posterior location

- Bilateral

- Cervical muscle tenderness

E. Cluster headache

- Duration 15-60 min

- Retro-orbital location

- Unilateral lacrimation, ptosis or eye redness 
- 1-4 headaches per day

F. Secondary headaches (cerebral pathology)

- Raised intracranial pressure

- Intracerebral hemorrhage

- Meningitis

- Abnormal neurological examination and/or neuroimaging

- sinusitis

G. Post dural puncture headache

i. At least 1 of the following after attempted or successful spinal or epidural anesthesia:

- Frontal/occipital headache

- Neck/shoulder pain or stiffness

ii. Associated with complete or partial relief when assuming the supine position

iii. Minimum of 4 hours duration

H. MSK pain

- Neck and/or shoulder pain unrelated to PDPH

I. Migrainous infarction

(a) migraine duration is either less than four hours or longer than $72 \mathrm{hr}$, but all other migraine criteria are met;

(b) the required endorsement of at least two pain characteristics is not met, but all other migraine criteria are met;

(c) no associated non-pain features are present (e.g., nausea, photophobia), but all other migraine criteria are met.

\section{References}

1 Goadsby PJ, Lipton RB, Ferrari MD. Migraine - Current understanding and treatment. N Engl J Med 2002; 346: 257-70.

2 Schulman EA. Overview of tension-type headache. Curr Pain Headache Rep 2001; 5: 454-62.

3 Edmeads J. The cervical spine and headache. Neurology 1988; 38: 1874-8.

4 Goadsby PJ. Trigeminal autonomic cephalgias (TACs). Acta Neurologica Belgica 2001; 101: 10-9.

5 Mannix LK. Epidemiology and impact of primary headache disorders. Med Clin North Am 2001; 85: 887-95.

6 Headache Classification Committee of the International Headache Society. Classification and diagnostic criteria for headache disorders, cranial neuralgias and facial pain. Cephalalgia 1988; 8(Suppl. 7): 1-96.

7 Benhamou D, Hamza J, Ducot B. Post partum headache after epidural analgesia without dural puncture. Int J Obstet Anesth 1995; 4: 17-20.

8 Stein G, Morton J, Marsh A, et al. Headaches after childbirth. Acta Neurol Scand 1984; 69: 74-9.

9 Breslow NE, Day NE. Case-control sampling within a cohort. In: Breslow NE, Day NE, (Eds). Statistical Methods In Cancer Research. Toronto: Oxford University Press; 1980: 289-91.

10 Stein GS. Headaches in the first post partum week and their relationship to migraine. Headache $1981 ; 21$ :

201-5.

11 Grove $L H$. Backache, headache and bladder dysfunction after delivery. Br J Anaesth 1973; 45: 1147-9.

12 Maggioni F, Alessi C, Maggino T, Zanchin G. Headache during pregnancy. Cephalalgia 1997; 17: 765-9.

13 Choi PT, Galinski SE, Takeuchi, Lucas S, Tamayo C, Jadad AR. PDPH is a common complication of neuraxial blockade in parturients: a meta-analysis of obstetrical studies. Can J Anesth 2003; 50: 460-9.

14 MacGregor EA. Oestrogen and attacks of migraine with and without aura. Lancet Neurol 2004; 3: 354-61.

15 Chan TML, Ahmed E, Yentis SM, Holdcroft A. Postpartum headaches: summary report of the National Obstetric Anaesthetic Database (NOAD) 1999. Int J Obstet Anesth 2003; 12: 107-12.

16 Angle P, Tang S, Thompson D, Szalai JP. Expectant management, postdural puncture headache and length of hospital stay. Anesthesiology 2002; 96(Suppl. 1): 99 (abstract).

17 Ponder TM. Differential diagnosis of postdural puncture headache in the parturient. CRNA 1999; 10: $145-54$ 